\title{
Remote Sensing of Atmospheric Hydrogen Fluoride (HF) over Hefei, China with Ground-Based High-Resolution Fourier Transform Infrared (FTIR) Spectrometry
}

\author{
Hao Yin ${ }^{1,2} \mathbb{D}$, Youwen Sun ${ }^{1,3, *}$, Cheng Liu ${ }^{1,2,3,4,5}$, Wei Wang ${ }^{1}$, Changgong Shan ${ }^{1}$ and Lingling Zha ${ }^{6}$ \\ 1 Key Laboratory of Environmental Optics and Technology, Anhui Institute of Optics and Fine Mechanics, \\ Hefei Institutes of Physical Science, Chinese Academy of Sciences, Hefei 230031, China; \\ yhyh95@mail.ustc.edu.cn (H.Y.); chliu81@ustc.edu.cn (C.L.); wwang@aiofm.ac.cn (W.W.); \\ cgshan@aiofm.ac.cn (C.S.) \\ 2 Department of Precision Machinery and Precision Instrumentation, University of Science and Technology of \\ China, Hefei 230026, China \\ 3 Center for Excellence in Regional Atmospheric Environment, Institute of Urban Environment, \\ Chinese Academy of Sciences, Xiamen 361021, China \\ 4 Key Laboratory of Precision Scientific Instrumentation of Anhui Higher Education Institutes, University of \\ Science and Technology of China, Hefei 230026, China \\ 5 Anhui Province Key Laboratory of Polar Environment and Global Change, University of Science and \\ Technology of China, Hefei 230026, China \\ 6 School of Biology, Food and Environment, Hefei University, Hefei 230022, China; llzha@aiofm.ac.cn \\ * Correspondence: ywsun@aiofm.ac.cn
}

check for updates

Citation: Yin, H.; Sun, Y.; Liu, C.; Wang, W.; Shan, C.; Zha, L. Remote Sensing of Atmospheric Hydrogen Fluoride (HF) over Hefei, China with Ground-Based High-Resolution Fourier Transform Infrared (FTIR) Spectrometry. Remote Sens. 2021, 13, 791. https://doi.org/10.3390/ rs13040791

Academic Editor: Beatriz Funatsu

Received: 28 January 2021

Accepted: 17 February 2021

Published: 21 February 2021

Publisher's Note: MDPI stays neutral with regard to jurisdictional claims in published maps and institutional affiliations.

Copyright: (C) 2021 by the authors. Licensee MDPI, Basel, Switzerland. This article is an open access article distributed under the terms and conditions of the Creative Commons Attribution (CC BY) license (https:// creativecommons.org/licenses/by/ $4.0 /)$.

\begin{abstract}
Remote sensing of atmospheric hydrogen fluoride (HF) is challenging because it has weak absorption signatures in the atmosphere and is surrounded by strong absorption lines from interfering gases. In this study, we first present a multi-year time series of HF total columns over Hefei, China by using high-resolution ground-based Fourier transform infrared (FTIR) spectrometry. Both near-infrared (NIR) and mid-infrared (MIR) solar spectra suites, which are recorded following the requirements of Total Carbon Column Observing Network (TCCON) and Network for the Detection of Atmospheric Composition Change (NDACC), respectively, are used to retrieve total column of $\mathrm{HF}\left(\mathrm{T}_{\mathrm{HF}}\right)$ and column-averaged dry-air mole fractions of $\mathrm{HF}\left(\mathrm{X}_{\mathrm{HF}}\right)$. The NIR and MIR observations are generally in good agreement with a correlation coefficient $(\mathrm{R})$ of 0.87 , but the NIR observations are found to be $(6.90 \pm 1.07(1 \sigma)) \mathrm{pptv}$, which is lower than the MIR observations. By correcting this bias, the combination of NIR and MIR observations discloses that the $\mathrm{X}_{\mathrm{HF}}$ over Hefei showed a maximum monthly mean value of $(64.05 \pm 3.93)$ pptv in March and a minimum monthly mean value of $(45.15 \pm 2.93)$ pptv in September. The observed $X_{\mathrm{HF}}$ time series from 2015 to 2020 showed a negative trend of $(-0.38 \pm 0.22) \%$ per year. The variability of $X_{\mathrm{HF}}$ is inversely correlated with the tropopause height, indicating that the variability of tropopause height is a key factor that drives the seasonal cycle of HF in the stratosphere. This study can enhance the understanding of ground-based high-resolution remote sensing techniques for atmospheric HF and its evolution in the stratosphere and contribute to forming new reliable remote sensing data for research on climate change.
\end{abstract}

Keywords: FTIR; stratosphere; hydrogen fluoride; near-infrared (NIR); mid-infrared (MIR)

\section{Introduction}

As a long-lived and chemical stable species in the stratosphere, hydrogen fluoride (HF) is a dominant reservoir of stratospheric fluorine species [1,2]. HF has a stratospheric lifetime on the order of more than 10 years [3]. Stratospheric HF is mainly produced from the photolysis of anthropogenic chlorofluorocarbons (CFCs) and hydrochlorofluorocarbons (HCFCs) [4,5]. Typically, stratospheric HF is removed by either transport downward to the troposphere and then wet deposited along with rainfall or transport upward to the 
mesosphere, where it is destroyed by photolysis [6,7]. Because anthropogenic fluoride emissions are major sources of $\mathrm{HF}$, the variability of $\mathrm{HF}$ provides a significant implication for evaluating the emissions of anthropogenic fluoride species $[3,7]$. Furthermore, monitoring HF as part of the atmospheric fluorine family plays an important role in assessing the fluorine budget, particularly as anthropogenic emissions of fluorine species, many of which are ozone-depleting and all of which are greenhouse (GHG) gases, have varied substantially over time. Indeed, monitoring the growth of stratospheric HF, which has slowed in recent years, is an important marker for the success of the Montreal Protocol (in addition to monitoring stratospheric $\mathrm{HCl}$ ).

The interannual trend of HF over the past decades has been estimated by many scientists, with measurements derived from ground-based, spaceborne, balloon, or airborne platforms. Rinsland et al. (2005) [8] reported a slowing down increasing trend of HF near $30^{\circ} \mathrm{N}$ latitude by comparing the spaceborne Fourier transform infrared (FTIR) measurements in 1985 and 1994 from the Atmospheric Trace Molecule Spectroscopy (ATMOS) experiment with the solar occultation measurements and in 2004 from the Atmospheric Chemistry Experiment-Fourier Transform Spectrometer (ACE-FTS). Harrison et al. (2015) [7] analyzed global interannual trends of HF by various observation methods. They revealed a substantial slowing down of the growth rate of HF since the 1990s, namely, $4.97 \pm 0.12 \%$ /year (1991-1997; the Halogen Occultation Experiment (HALOE)), $1.12 \pm 0.08 \%$ /year (1998-2005; HALOE), and $0.52 \pm 0.03 \%$ /year (2004-2012; ACE-FTS). However, Steffen et al. (2019) [2] found the interannual trend of HF is $0.83 \pm 0.07 \%$ /year from 2004 to 2011 (ACE-FTS), which is higher than the result of Harrison et al. (2015). With ground-based FTIR measurements affiliated to the Network for the Detection of Atmospheric Composition Change (NDACC), Mikuteit et al. (2008) [4,9] reported an increasing interannual trend in the HF column by $1.0 \pm 0.3 \%$ /year from 1996 to 2008 over Kiruna, Sweden. Meanwhile, Kohlhepp et al. (2011) [10] found an increasing interannual trend in HF total column by 0.5\%/year-2\%/year at most NDACC stations between 2000 to 2009 .

High-resolution direct solar FTIR spectrometry is the most precise ground-based remote sensing technique to derive column-averaged abundances of greenhouse gases (GHGs) or mixing ratio profiles of many other trace gases [11-14]. Currently, both the two well-established operational observation networks, i.e., the NDACC and the Total Carbon Column Observing Network (TCCON, http:/ / www.tccon.caltech.edu/, accessed on 2 December 2020), use high-resolution FTIR spectrometers to record direct sun spectra. Both networks have operated internationally for more than $\mathrm{t} 10$ years and the results are widely used in atmospheric physics and chemistry [11-15]. There are more than 20 groundbased FTIR sites around the globe, and some of them are affiliated with both NDACC and TCCON networks $[16,17]$. HF is one of the target gases of both networks. However, most FTIR instruments are located in Europe and North America, but the number of observation sites in the rest parts of the world remains scarce, and there is only one qualified observations site in China, i.e., the Hefei site $\left(117^{\circ} \mathrm{E}, 32^{\circ} \mathrm{N}, 30 \mathrm{~m}\right.$ above sea level (a.s.l.)) located in a densely populated and industrialized area in eastern China [18]. As a result, the coverage of ground-based HF measurements around the globe remains sparse [18-24].

In this study, we first present and analyze the variability of HF over densely populated and industrialized eastern China by using ground-based high-resolution FTIR spectrometry. The HF retrievals with near-infrared (NIR) and mid-infrared (MIR) observations are compared. The seasonality and interannual variability of HF over Hefei, eastern China from 2015 to 2020 are investigated with the combination of NIR and MIR observations. Finally, the potential factors that drive the observed seasonality of HF are analyzed. This study can enhance the understanding of ground-based high-resolution remote sensing techniques for atmospheric HF and its evolution in the stratosphere and contribute to new reliable remote sensing data in this sparsely monitored region for research on climate change.

This study is organized as follows. The next section describes the methodology including site description and instrumentation, retrieval strategies for NIR and MIR observations, 
the second regression model for determining the seasonal and interannual variabilities of $\mathrm{HF}$, strategies for comparing NIR and MIR retrievals, and the data filter criteria. Section 3 reports the results for comparison between NIR and MIR retrievals, and the seasonality and interannual trend of HF over Hefei. Section 4 investigates potential factors driving the observed variability of HF. We conclude this study in Section 5.

\section{Materials and Methods}

\subsection{Site Description and FTIR Instrumentation}

The ground-based high-resolution FTIR observation site $\left(117^{\circ} 10^{\prime} \mathrm{E}, 31^{\circ} 54^{\prime} \mathrm{N}, 30 \mathrm{~m}\right.$ a.s.l.) is located in the western suburbs of Hefei (the capital of Anhui Province) in centraleastern China. This FTIR observatory is operated by the Anhui Institute of Optics and Fine Mechanics, Chinese Academy of Sciences (AIOFM-CAS), which has recorded solar spectra since April 2014 [18-24]. As one of the few FITR stations in Asia, FTIR observations at Hefei have been used extensively for evaluation of satellite data [21,22], chemical model simulation $[21,23,24]$, local air quality $[18,25]$, and the transport of air pollutants caused by anthropogenic and biomass burning emissions [18,26].

The FTIR observatory at Hefei consists of a high-resolution FTIR spectrometer (IFS125HR, Bruker GmbH, Ettlingen, Germany), a solar tracker (Tracker-A Solar 547, Bruker GmbH, Ettlingen, Germany), and a weather station (ZENO 3200, Coastal Environmental Systems, Inc., Seattle, USA). The instrument has been operating almost continuously since its installation in April 2014; however, short data gaps of up to two months have occurred due to an interferogram problem between December 2014 and February 2015. Before July 2015, the FTIR instrument was operated following the TCCON requirements and only recorded NIR solar spectra. Thereafter, we set up the FTIR instrument to run the NDACC observations in the MIR spectral range. Henceforth, this FTIR observatory alternately recorded NIR and MIR solar spectra in routine observations [21]. The NIR and MIR spectra are recorded with different spectral resolutions but both of them can be used to retrieve total columns and volume mixing ratio (VMR) profiles of a variety of trace gases in the atmosphere.

The FTIR instrument at Hefei contains nine optical compartments that can reach a maximum optical path difference (OPD) of $900 \mathrm{~cm}$. Calculated as the empirical formula of $0.9 / \mathrm{OPD}$, this instrument can reach the highest spectral resolution of $0.001 \mathrm{~cm}^{-1}$. However, the NIR and MIR spectra are recorded with a spectral resolution of $0.02 \mathrm{~cm}^{-1}$ and $0.005 \mathrm{~cm}^{-1}$, respectively, to follow the TCCON and NDACC conventions. These spectral resolutions are sufficient to resolve the optical absorption structure of all gases in the atmosphere because atmospheric absorption lines of all gases are expanded as a result of pressure and temperature broadening. Using these proper resolutions rather than the highest nominal spectral resolution speeds up the spectral acquisition and modeling time without deteriorating the observation accuracy. In this study, the instrument is equipped with a $\mathrm{KBr}$ beam splitter, an indium antimonide ( $\mathrm{InSb}$ ) detector, and a filter centered at $4200 \mathrm{~cm}^{-1}$ for HF measurements in the MIR range, and a $\mathrm{CaF}_{2}$ beam splitter and an InGaAs detector for HF measurements in the NIR range. For the NIR spectra, the entrance field stop size was restricted to $1 \mathrm{~mm}$ for all measurements. For the MIR spectra, the entrance field stop size ranging from $0.80 \mathrm{~mm}$ to $1.5 \mathrm{~mm}$ was employed to maximize the signal-to-noise ratio (SNR) consistent with the maximum frequency possible for the selected wavenumber range. The number of measurements within a day varies from 1 to 30 .

\subsection{Retrieval Strategy for NIR Spectra Suite}

The NIR spectra suite were processed with the TCCON standard analysis software GGG [13] (https:/ / data.caltech.edu/records/293, accessed on 2 December 2020). GGG is a suite of software tools centrally maintained at the Jet Propulsion Laboratory, California Institute of Technology (JPL, Caltech) to derive the total column of atmospheric trace gases from NIR solar spectra. Each TCCON site uses the same version of the software and the processing procedures to make sure the retrievals are consistent from site to site [27]. In this study, the latest version of the GGG 2014 was used. The first step is to 
convert the raw data (interferograms) into spectra, using a subroutine procedure called interferogram-to-spectrum (I2S). A priori profiles of pressure, temperature, and $\mathrm{H}_{2} \mathrm{O}$ are from the National Center for Environmental Protection/National Center for Atmospheric Research (NCEP/NCAR) reanalysis. A subroutine procedure called "GSETUP" is then run to generate a priori profiles of $\mathrm{HF}$ and other trace gases. This procedure takes into account a series of problems, including a secular increase, interhemispheric gradient, seasonal cycle, and stratospheric decay based on the age of air. The spectra are then passed into the nonlinear least-squares spectral fitting subroutine "GFIT" that iteratively scales the a priori profiles to generate forward-modeled spectra until the best fit to the measured spectrum (Figure 1).

(a)

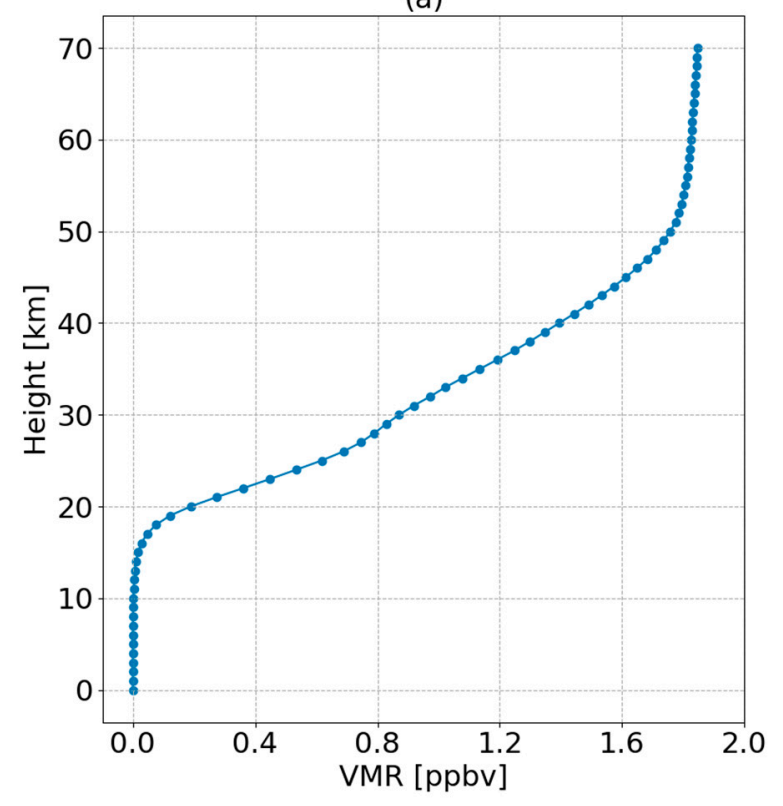

(b)

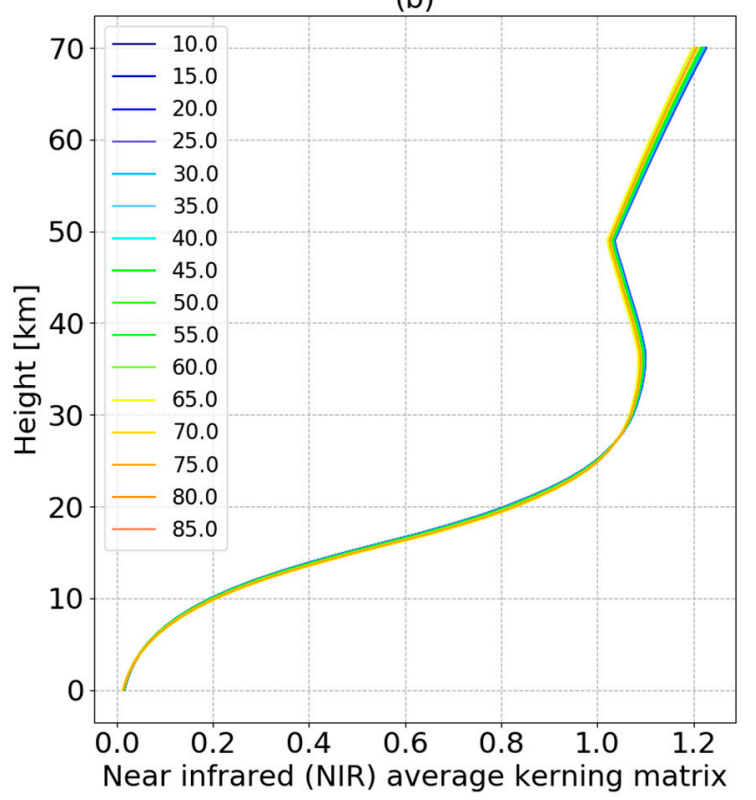

Figure 1. (a) The a priori profile and (b) the averaging kernel (AVK) matrix for hydrogen fluoride (HF) retrieval with GGG2014 at Hefei, China.

In addition to $\mathrm{HF}$ retrieval, the $\mathrm{O}_{2}$ total column is also retrieved to convert the HF total column into column-averaged dry-air mole fractions of $\mathrm{HF}\left(\mathrm{X}_{\mathrm{HF}}\right)$. The retrieval setups for $\mathrm{HF}$ and $\mathrm{O}_{2}$ in NIR spectra suite using GGG2014 are summarized in Table 1 [28]. As described in Wunch et al. (2011) [13] and Wunch et al. (2015) [27], HF is retrieved in the $4038.79-4039.11 \mathrm{~cm}^{-1}$ spectral window, and $\mathrm{O}_{2}$ is retrieved in the $7765.0-8005.0 \mathrm{~cm}^{-1}$ spectral window. The interfering absorption of $\mathrm{H}_{2} \mathrm{O}$ is considered in the $\mathrm{HF}$ window, and the interfering absorptions of $\mathrm{H}_{2} \mathrm{O}, \mathrm{HF}$, and $\mathrm{CO}_{2}$ are considered in the $\mathrm{O}_{2}$ window. Spectroscopic absorption parameters of all gases are based on the HITRAN (High Resolution Transmission) 2008 line-list database $[29,30]$. To calculate $\mathrm{X}_{\mathrm{HF}}$, the $\mathrm{HF}$ total column is divided by the total column of dry air, which is deduced by using a co-retrieved $\mathrm{O}_{2}$ total column divided by an assumed dry-air mole fraction of $\mathrm{O}_{2}$ (0.2095).

$$
\mathrm{TC}_{\mathrm{air}}=\frac{\mathrm{TC}_{\mathrm{O}_{2}}}{0.2095}
$$

where $\mathrm{TC}_{\text {air }}$ represents the total column of dry air and $\mathrm{TC}_{\mathrm{O}_{2}}$ represents the total column of $\mathrm{O}_{2}$. As a result, $\mathrm{X}_{\mathrm{HF}}$ can be expressed as

$$
\mathrm{X}_{\mathrm{HF}}=\frac{\mathrm{TC}_{\mathrm{HF}}}{\mathrm{TC}_{\mathrm{air}}}=\frac{\mathrm{TC}_{\mathrm{HF}}}{\mathrm{TC}_{\mathrm{O}_{2}}} \times 0.2095
$$


In order to achieve consistent results between different FTIR sites around the globe, the TCCON network has developed a strict data acquisition and retrieval algorithm to attempt to minimize the site-to-site difference. Because the NIR spectra acquisition and retrieval at Hefei follow the TCCON convention, we assume the error budget for HF within the TCCON network applies to that at Hefei. Wunch et al. (2011) [13] proceeded a sensitivity study, whereby each source of error is perturbed by a realistic amount in the GFIT forward model, and the fractional difference for each error source, relative to the unperturbed case, is computed. These sensitivities are computed for spectra from a clear day in Lamont, over a large difference in atmospheric water vapor, and a large range of solar zenith angles (SZAs) and surface temperatures. The total error is the sum in quadrature of each individual uncertainty. HF has only a single absorption line located on the edge of a strong water absorption line, so the retrievals tend to be quite noisy, especially at high solar zenith angles. According to the sensitivity study by Wunch et al. (2015) [27], the total errors of $\mathrm{X}_{\mathrm{HF}}$ are at or less than $8 \%$ below $80^{\circ}$ SZAs. The dominant sources are the $a$ priori profile shape, shear misalignment, and angular misalignment. The $a$ priori profile and the averaging kernel (AVK) matrix for HF retrieval with GGG2014 are shown in Figure 2. It shows that HF retrievals at Hefei with NIR spectra suite have a sensitivity of larger than 0.5 above $\sim 15 \mathrm{~km}$ and are SZA independent, indicating that the retrievals are mainly sensitive to the stratosphere regardless of observation scenario. This also means that the retrieval information with NIR spectra suite in the stratosphere comes for more than $50 \%$ from the measurement, or in other words, that the a priori information impacts the retrieval by less than $50 \%$.
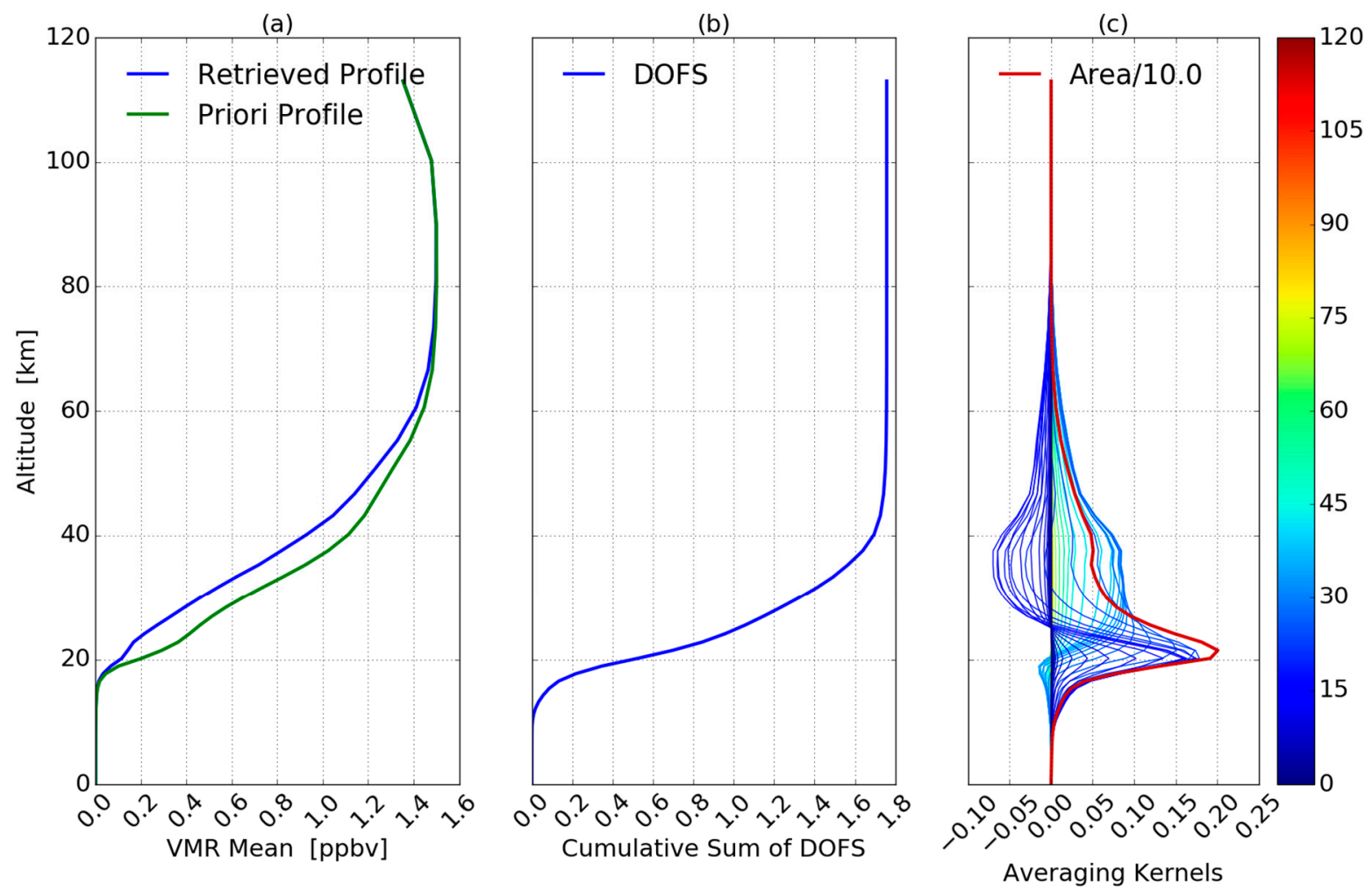

Figure 2. (a) The a priori and retrieved volume mixing ratio (VMR) profiles of HF, (b) cumulative sum of the degrees of freedom for signal (DOFs), (c) the averaging kernel (AVK) matrix $\mathbf{A}$ and their area for randomly selected HF retrieval with MIR spectra suite at Hefei, China. 
Table 1. Retrieval setups for $\mathrm{HF}$ and $\mathrm{O}_{2}$ in near-infrared (NIR) spectra suite using GGG2014 at Hefei, China.

\begin{tabular}{ccc}
\hline Gases & HF & O $_{2}$ \\
\hline Retrieval code & GGG2014 & GGG2014 \\
\hline Spectroscopy & HITRAN2008 & HITRAN2008 \\
\hline Pressure, Temperature profiles & NCEP & NCEP \\
\hline A priori profiles for all gases & GGG2014 code & GGG2014 code \\
\hline MW for profile retrievals $\left(\mathrm{cm}^{-1}\right)$ & $4038.79-4039.11$ & $7765-8005$ \\
\hline Window Width $\left(\mathrm{cm}^{-1}\right)$ & 0.32 & 240 \\
\hline Retrieved interfering gases & $\mathrm{H}_{2} \mathrm{O}$ & $\mathrm{CO}_{2}, \mathrm{H}_{2} \mathrm{O}, \mathrm{HF}$ \\
\hline
\end{tabular}

\subsection{Retrieval Strategy for MIR Spectra Suite}

The SFIT4 (version 0.9.4.4) algorithm is used to retrieve the vertical VMR profiles of HF from the MIR solar spectra suite. Micro windows (MWs) selection and the interfering gases consideration in this study follow the NDACC recommendation (https:/ / www2 .acom.ucar.edu/irwg/links, last access on 31 December 2020). The retrieval inputs for HF are summarized in Table 2. The monthly mean profiles of all gases except water vapor $\left(\mathrm{H}_{2} \mathrm{O}\right)$ from the statistical averages of the Whole-Atmosphere Community Climate Model (WACCM) version 6 simulations from 1980 to 2020 are used as the a priori profiles of the corresponding gases. The a priori profiles of $\mathrm{H}_{2} \mathrm{O}$, pressure, and temperature are interpolated from the National Centers for Environmental Protection/National Center for Atmospheric Research (NCEP/NCAR) six-hourly reanalysis data [28]. A narrow MW of 4109.4-4110.2 $\mathrm{cm}^{-1}$ was used to retrieve the VMR profile of HF. In this retrieval window, $\mathrm{CH}_{4}, \mathrm{HDO}$, and $\mathrm{H}_{2} \mathrm{O}$ show absorption interference with HF. In order to minimize these atmospheric absorption interferences, the VMR profile of $\mathrm{H}_{2} \mathrm{O}$ and total columns of $\mathrm{CH}_{4}$ and HDO were also retrieved together with the HF VMR profile. No de-weighting signalto-noise ratio (SNR) is used for HF. The same as the usage in HF retrieval with NIR spectra suite (Section 2.2), the spectroscopic line parameters of all gases are also provided by the HITRAN 2008 database [29,30].

Table 2. The input parameters for HF retrieval at Hefei with mid-infrared (MIR) spectra suite.

\begin{tabular}{|c|c|}
\hline Gases & HF \\
\hline Retrieval code & SFIT4 v 0.9.4.4 \\
\hline Spectroscopy & HITRAN2008 \\
\hline $\mathrm{P}, \mathrm{T}$ profiles & NCEP \\
\hline A priori profiles for all gases except $\mathrm{H}_{2} \mathrm{O}$ & WACCM v6 \\
\hline MW for profile retrievals $\left(\mathrm{cm}^{-1}\right)$ & $4109.4-4110.20$ \\
\hline Window Width $\left(\mathrm{cm}^{-1}\right)$ & 0.8 \\
\hline Retrieved interfering gases & $\mathrm{CH}_{4}, \mathrm{HDO}$ and $\mathrm{H}_{2} \mathrm{O}$ \\
\hline De-weighting SNR & None \\
\hline \multirow{2}{*}{ Regularization } & WACCM Std \\
\hline & Real SNR \\
\hline ILS & LINEFIT145 \\
\hline
\end{tabular}

With respect to retrieval regularization, the diagonal elements of the measurement noise covariance matrix $S_{\varepsilon}$ were set to the square inverse of the SNR of each fitting spectrum, and its non-diagonal elements were set to zero. For all gases, we set the diagonal elements of a priori profile covariance matrices $S_{a}$ to standard deviations of the WACCM model 
results from 1980 to 2020, and their non-diagonal elements to zero. We included the real instrumental line shape (ILS) derived from a low-pressure $\mathrm{HBr}$ cell measurement with the LINEFIT 145 package in the retrieval $[26,31,32]$.

The vertical information of the FTIR retrieval can be characterized by the AVK matrix A. The area of $\mathbf{A}$ indicates the retrieval sensitivity at each vertical layer. The degrees of freedom for signal (DOFS), which was calculated by the trace of $\mathbf{A}$ represents the number of independent information contained in the retrieval. The a priori and retrieved profiles, the cumulative sum of DOFS, and the AVKs and their area for randomly selected HF retrieval with MIR spectra suite at Hefei are shown in Figure 2a-c, respectively. Ground-based FTIR measurement of HF at Hefei in the MIR range has a sensitivity of larger than 0.5 from about $18 \mathrm{~km}$ to $38 \mathrm{~km}$ altitude, indicating that the MIR retrieval is mainly sensitive to the stratosphere. This also means that the retrieved profile information in the stratosphere comes for more than $50 \%$ from the measurement, or in other words, that the a priori information impacts the retrieval by less than $50 \%$. The typical DOFS obtained at Hefei over the total atmosphere for HF is 1.76, meaning that we can get less than two pieces of information on the vertical profile. As a result, only total columns of HF or columnaveraged dry-air mole fractions of HF are discussed in this study and not vertical profiles. The retrieved total column tends to be strongly influenced by surface pressure, and hence, topography. Column-averaged dry-air mole fraction is less sensitive to the variations in surface pressure and atmospheric water vapor than the total column. This characteristic is advantageous for atmospheric cycle studies because it permits direct comparisons of the measurements during different seasons between sites and with in situ measurements [27]. The total column of HF is calculated by integrating the retrieved HF VMR profile from the surface to the top of the atmosphere. The $\mathrm{X}_{\mathrm{HF}}$ value is calculated by taking a weighting average of the HF VMR profile and the air mass over the total atmosphere. As shown in Figure 2, the shape of the retrieved profile is similar to the shape of the a priori profile due to the low DOFS and is heavily weighted toward the stratosphere.

The formalism of Rodgers [33] was used to calculate the error budget of HF at Hefei $[33,34]$. We separated all error components into systematic or random errors depending on whether they are constant over consecutive measurements, or vary randomly. In this study, the random error contains temperature uncertainty, retrieval parameter uncertainty, interfering species uncertainty, measurement error, and smoothing error. The systematic error contains background curvature uncertainty, optical path difference uncertainty, field of view uncertainty, solar line shift uncertainty, solar line strength uncertainty, phase uncertainty, line temperature broadening uncertainty, line pressure broadening uncertainty, and line intensity uncertainty. Table 3 summarizes the random, systematic, and the combined error budget for HF retrieval demonstrated in Figure 2. The input covariance matrix of temperature has been estimated using the differences between an ensemble of NCEP and Sonde temperature profiles near Hefei, leading to $2 \mathrm{~K}$ to $5 \mathrm{~K}$ in the troposphere and $3 \mathrm{~K}$ to $7 \mathrm{~K}$ in the stratosphere. For each interfering species, the associated covariance matrix was obtained with the WACCM v6 climatology. The input covariance matrix of measurement error is based on the inverse square of the SNR of each spectrum. The FTIR instrument at Hefei is assumed to be not far from the ideal condition, and the input uncertainties for background curvature, optical path difference, the field of view, and interferogram phase are estimated to be $0.1 \%$. Solar line strength and shift uncertainties are also estimated to be $0.1 \%$. For the HF spectroscopic parameters, we use $5 \%$ for line intensity, pressure, and temperature-broadening coefficients. For each individual retrieval parameter and the smoothing error, the input covariance matrix is prescribed from the optimal estimation retrieval output.

We see from Table 3 that the dominant random error for HF retrieval at Hefei is temperature uncertainty $(0.41 \%)$ and the dominant systematic error is line intensity uncertainty (5.0\%). Total random and systematic errors are estimated to be $0.51 \%$ and $5.15 \%$, respectively. Total retrieval error calculated as square root sum of the squares of totally random and systematic errors is estimated to be $5.18 \%$. 
Table 3. Individual error component for retrieval of HF total column over Hefei, China.

\begin{tabular}{ccc}
\hline Gases & $\mathbf{K}_{\mathbf{b}}$ & $\mathbf{H F}$ \\
\hline Temperature uncertainty & SD of NCEP & $0.41 \%$ \\
Retrieval parameters uncertainty & $*$ & $<0.01 \%$ \\
Interfering species uncertainty & $*$ & $<0.01 \%$ \\
Measurement error & $*$ & $0.29 \%$ \\
Smoothing uncertainty & $*$ & $0.15 \%$ \\
Total random error & $/$ & $0.52 \%$ \\
\hline Background curvature uncertainty & $0.1 \%$ & $0.03 \%$ \\
Optical path difference uncertainty & $0.1 \%$ & $<0.01 \%$ \\
Field of view uncertainty & $0.1 \%$ & $<0.01 \%$ \\
Solar line strength uncertainty & $0.1 \%$ & $<0.01 \%$ \\
Solar line shift uncertainty & $0.1 \%$ & $<0.01 \%$ \\
Phase uncertainty & $0.1 \%$ & $0.01 \%$ \\
Line temperature broadening uncertainty & $5 \%$ & $1.22 \%$ \\
Line pressure broadening uncertainty & $5 \%$ & $5.00 \%$ \\
Line intensity uncertainty & $5 \%$ & $5.15 \%$ \\
Total systematic error & $/$ & $5.18 \%$ \\
\hline Total error & $/$ & 1.76 \\
\hline DOFS (-) & $/$ & \\
\hline
\end{tabular}

* These input parameters used for error estimation are prescribed from the retrieval process.

\subsection{Regression Model for Seasonality and Interannual Trend}

We have used a bootstrap resampling model to determine the seasonality and interannual variability of HF from 2015 to 2020 over Hefei, China. The resampling methodology follows that of Gardiner [35], where a second Fourier series plus a linear function were used to fit multi-year time series of $\mathrm{X}_{\mathrm{HF}}$ daily mean. The measurements are used on a daily basis to lower the regression residual and improve the fitting correlation. Many studies have verified the robustness of Gardiner's methodology in modeling the seasonality and interannual variabilities of a series of atmospheric species. In this study, the relationship between the measured $\mathrm{X}_{\mathrm{HF}}$ daily mean time series and the regression model can be expressed as

$$
\begin{gathered}
\mathrm{V}(\mathrm{t}, \mathbf{b})=\mathrm{b}_{0}+\mathrm{b}_{1} \mathrm{t}+\mathrm{b}_{2} \cos \left(\frac{2 \pi \mathrm{t}}{365}\right)+\mathrm{b}_{3} \sin \left(\frac{2 \pi \mathrm{t}}{365}\right) \\
\mathrm{F}(\mathrm{t}, \mathrm{a}, \mathbf{b})=\mathrm{V}(\mathrm{t}, \mathbf{b})+\varepsilon(\mathrm{t}) \\
\mathrm{d} \%=\frac{\mathrm{F}(\mathrm{t}, \mathrm{a}, \mathbf{b})-\mathrm{V}(\mathrm{t}, \mathbf{b})}{\mathrm{F}(\mathrm{t}, \mathrm{a}, \mathbf{b})} \times 100 \%
\end{gathered}
$$

where $F(t, a, b)$ and $V(t, b)$ represent the measured and fitted $X_{H F}$ time series, respectively. The parameters $b_{0}, b_{1}, b_{2}$, and $b_{3}$ contained in the vector $\mathbf{b}$ are coefficients obtained from the bootstrap resampling regression fit with $V(t, b) . b_{0}$ is the intercept, $b_{1}$ is the annual growth rate, and $b_{1} / b_{0}$ is the interannual trend discussed below. The $b_{2}-b_{3}$ parameters describe the seasonal cycle, $t$ is the measurement time (fractional of the year) elapsed since 2015 , and $\varepsilon(t)$ represents the residuals between the measurements and the fitting model. Note that the autocorrelation in the residual can increase the uncertainty in the calculation of interannual trends. In order to take into account this influence, we incorporated the error arising from the autocorrelation in the residual into the uncertainty in the trend following the procedure of Santer et al. (2008) [36]. In addition, fractional differences of FTIR $X_{H F}$ time series relative to their seasonal mean values represented by $\mathrm{V}(\mathrm{t}, \mathbf{b})$ were calculated in Equation (5) to analyse seasonal enhancements.

\subsection{Strategy for Comparing the NIR and MIR Retrievals}

The NIR and MIR observations over Hefei were performed using the same instrument, however, the acquisition hardware, including the detector, beam-splitter, and optical filter, 
and the retrieval strategies, including retrieval micro windows, spectral modeling method, and the iterative scheme for these observations are different, which would cause the difference in retrieval results. According to Rodgers (2000) [33], the retrieved FTIR (NIR and MIR) HF total column related to the true state of the atmosphere and the a priori information can be expressed as

$$
\mathrm{TC}_{\mathrm{r}}=\mathrm{TC}_{\mathrm{a}}+\mathrm{A}\left(\mathrm{PC}_{\mathrm{t}}-\mathrm{PC}_{\mathrm{a}}\right)+\varepsilon
$$

where $\mathrm{TC}_{\mathrm{r}}$ and $\mathrm{TC}_{\mathrm{a}}$ are the retrieved and a priori $\mathrm{HF}$ total columns, respectively; $\mathrm{PC}_{\mathrm{a}}$ and $\mathrm{PC}_{\mathrm{t}}$ are the a priori and the true HF partial columns, respectively; $\mathrm{A}$ is the column averaging kernels (AVKs) of the NIR and MIR retrievals, representing the vertical sensitivity of the retrieved HF to the true state; and $\varepsilon$ is the error. As a result, the difference in HF total column between NIR and MIR measurements $\left(\mathrm{T}_{\text {HF,NIR }}\right.$ and $\left.\mathrm{T}_{\mathrm{HF}, \mathrm{MIR}}\right)$ can be represented as follows:

$$
\mathrm{T}_{\mathrm{HF}, \mathrm{NIR}}-\mathrm{T}_{\mathrm{HF}, \mathrm{MIR}}=\left(\mathrm{X}_{\mathrm{NIR}}^{\text {apriori }}-\mathrm{X}_{\mathrm{MIR}}^{\text {apriori }}\right)+\left(\mathrm{A}_{\mathrm{NIR}}-\mathrm{A}_{\mathrm{MIR}}\right) \mathrm{X}_{\text {true }}+\left(\mathrm{A}_{\mathrm{NIR}} \mathrm{X}_{\mathrm{NIR}}^{\text {apriori }}-\mathrm{A}_{\mathrm{MIR}} \mathrm{X}_{\mathrm{MIR}}^{\text {apriori }}\right)
$$

where $A_{N I R}$ and $A_{M I R}$ represent the AVKs of the NIR and MIR retrievals, respectively. $X_{\text {true }}$ is the $X_{\mathrm{HF}}$ in the real state and $\mathrm{X}_{\mathrm{NIR}}^{\text {apriori }}$ and $\mathrm{X}_{\mathrm{MIR}}^{\text {apriori }}$ are a priori profiles of HF for NIR and MIR measurements. Therefore, apart from the different sensitivity of the forward model to the underlying true state in different retrieval windows, e.g., on account of spectroscopic differences, the following two factors dominate the differences between NIR and MIR measurements: (a) the differences in a priori profiles and (b) the differences in AVKs. In order to compare the NIR and MIR data properly, we followed the method of Rodgers et al. (2003) [34] and mapped all NIR data into MIR retrieval scenarios by using the MIR AVKs and a priori profiles. First, the NIR daily mean profiles of HF were interpolated to the MIR altitude grid to ensure a common altitude grid. The a priori profile correction is then applied to the interpolated NIR profiles by

$$
\mathrm{X}_{\mathrm{NIR}}^{\prime}=\mathrm{X}_{\mathrm{NIR}}+\left(\mathrm{A}_{\mathrm{NIR}}-\mathrm{I}\right)\left(\mathrm{X}_{\mathrm{NIR}}^{\text {apriori }}-\mathrm{X}_{\mathrm{MIR}}^{\text {apriori }}\right)
$$

where $\mathrm{X}_{\mathrm{NIR}}$ is the original NIR data, $\mathrm{X}_{\mathrm{NIR}}^{\prime}$ is the a priori profile corrected NIR data, $\mathrm{I}$ is the unity diagonal matrix. Afterward, the smoothing correction is applied to the a priori profile corrected NIR data by

$$
\mathrm{X}_{\mathrm{NIR}}^{\prime \prime}=\mathrm{X}_{\mathrm{MIR}}^{\text {apriori }}+\mathrm{A}_{\mathrm{MIR}}\left(\mathrm{X}_{\mathrm{NIR}}^{\prime}-\mathrm{X}_{\mathrm{MIR}}^{\text {apriori }}\right)
$$

where $\mathrm{X}_{\mathrm{NIR}}^{\prime \prime}$ is the result after a priori profile and smoothing corrections, and we use it to compare with the corresponding MIR data.

\subsection{Data Filter Criteria}

In order to exclude the measurements seriously affected by unstable weather conditions or by the a priori profile due to low measurement information content in less favorable observational conditions, we established a series of filter criteria to remove the outliers by setting certain thresholds for measurement intensity, fitting error, DOFS, and fitting residuals. Measurements satisfying the criteria as follows were classified as valid and were subsequently used in the analysis. With these criteria, $22.4 \%$ of FTIR measurements were excluded.

(1) Spectra recorded with incident signals lower than a threshold are discarded to ensure adequate SNRs. Meanwhile, spectra recorded with incident signals higher than a threshold are also discarded to avoid non-linearity in the detector. Specifically, for NIR spectra recorded with $\mathrm{CaF}_{2}$ beam splitter, the signal intensity should lie in between 8000 and 25,000 direct current (DC) counts, and for MIR spectra recorded with InSb detector, the signal intensity should lie in between 10,000 and 20,000 DC counts; 
(2) The auxiliary data such as solar intensity and meteorological data (at least surface pressure and temperature) should be recorded synchronously with the measurements. Otherwise, the measurements are screened out;

(3) The observed scene must be nearly cloud-free and not seriously affected by smog or unknown opaque object. The spectra recorded with a solar intensity variation (SIV) of larger than $10 \%$ were not used in this study. The SIV within the duration of a spectrum is the ratio of the standard deviation to the average of the sun intensities;

(4) The root mean square error (RMS) of the residual difference (the relative difference between measured and calculated spectra after the fit) in all fitting windows has to be less than 3\% for NIR spectra and5\% for MIR spectra;

(5) For profile retrieval with MIR spectra, the retrievals should be converged, and the concentrations of the target and interfering gases at each sub-layer should be positive. The total DOFs should be larger than 0.6 to ensure that the retrieval comes more from measurement rather than a priori information;

(6) The SZA should be less than $85^{\circ}$ for both NIR and MIR spectra.

\section{Results}

\subsection{Comparison between NIR and MIR Retrievals}

In order to balance the number of NIR and MIR measurements, the NIR and MIR spectra are collected alternately in routine observations. This section compares the NIR and MIR HF measurements over Hefei to understand the discrepancies between these two datasets better and to know whether these two datasets can be combined to form more reliable data for evaluation, seasonal cycles, and long-term trend analyses. All NIR daily mean time series from 2015 to 2020 were mapped into the MIR retrieval scenarios following the procedures in Section 2.5 and compared with the concurrent MIR data. Figure 3a shows the comparison of the daily mean time series of $\mathrm{X}_{\mathrm{HF}}$ between NIR and MIR observations from 2015 to 2020. Figure 3b compares the seasonal cycles derived from Figure 3a through averaging the concurrent data pairs by month. Correlation plots of NIR measurements against MIR measurements are shown in Figure 4.

(a)

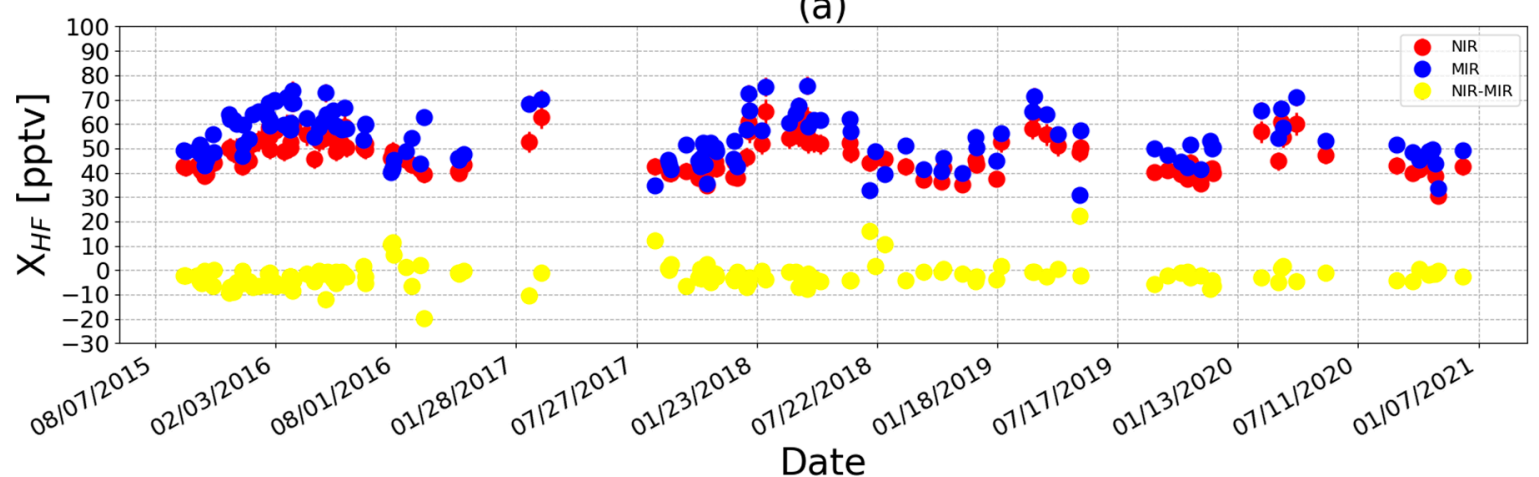

(b)

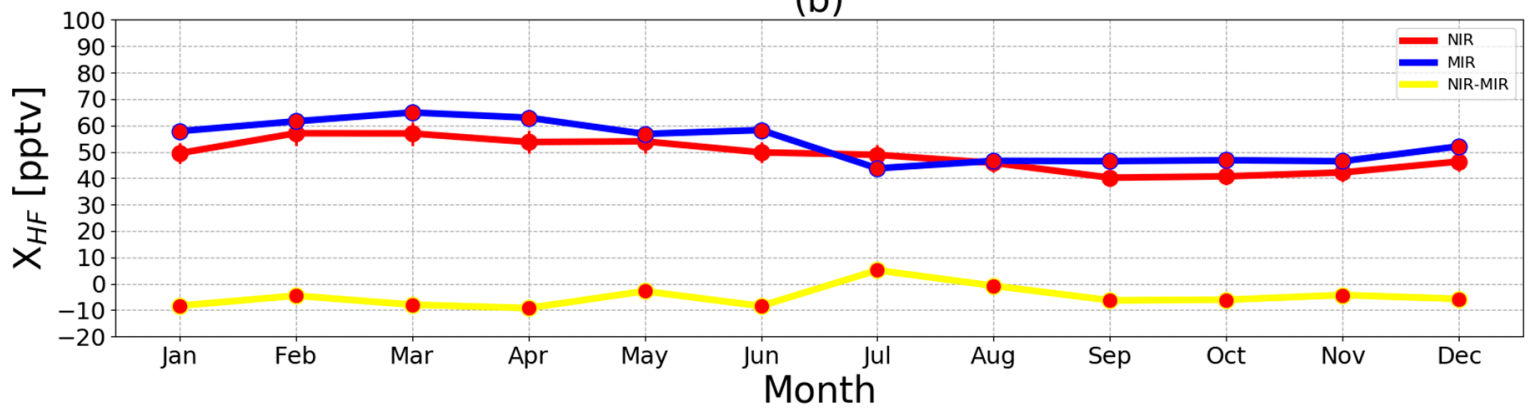

Figure 3. (a) Daily mean differences between NIR and MIR retrievals of $\mathrm{X}_{\mathrm{HF}}$ at Hefei. (b) Same as (a), but for monthly mean differences. 


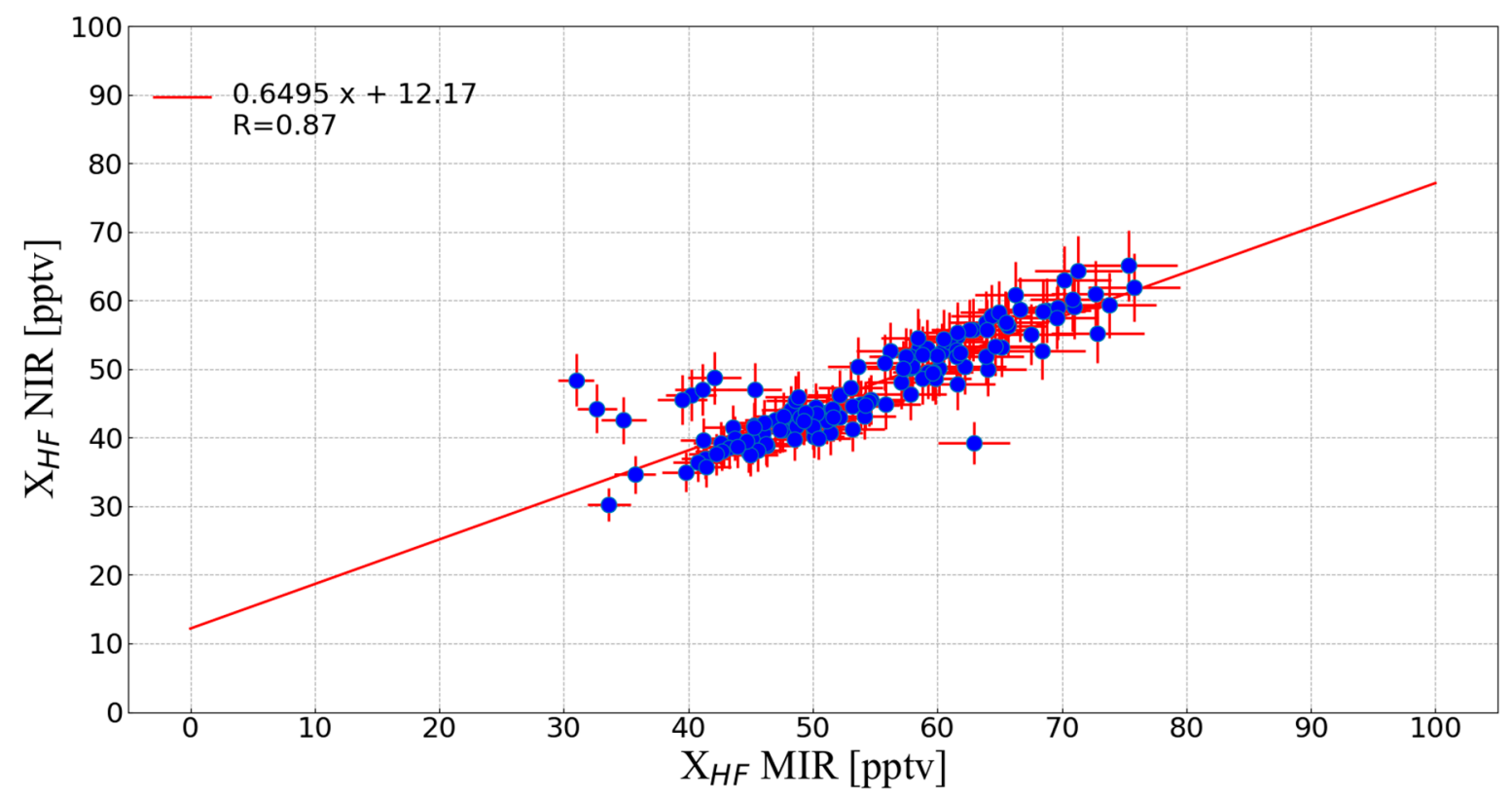

Figure 4. Correlation plots of NIR $\mathrm{X}_{\mathrm{HF}}$ measurements against MIR $\mathrm{X}_{\mathrm{HF}}$ measurements. The red line is the linear fitted curve of respective scatter points.

The results show that NIR and MIR $\mathrm{X}_{\mathrm{HF}}$ data exhibit consistent seasonality but the daily mean time series of NIR $X_{\mathrm{HF}}$ data are generally lower than the MIR data, with an average difference of $(6.90 \pm 1.07) \mathrm{pptv}\left(\mathrm{X}_{\mathrm{HF}, \mathrm{NIR}}-\mathrm{X}_{\mathrm{HF}, \mathrm{MIR}}\right)$. The monthly mean difference of NIR and MIR data shows the largest difference in April with a value of $(-9.23 \pm 7.15)$ pptv and the lowest difference in August with a value of $(-0.79 \pm 5.92)$ pptv $\left(\mathrm{X}_{\mathrm{HF}, \mathrm{NIR}}-\right.$ $\left.X_{\mathrm{HF}, \mathrm{MIR}}\right)$. For all months, the monthly mean differences between NIR and MIR are within 10 pptv. Considering the amplitude of $\mathrm{X}_{\mathrm{HF}}$ is different seasonally, we further analyzed the variations of the fractional difference to minimize this seasonal influence. The fractional difference is calculated as the ratio of the absolute difference to the amplitude of each respective month. We found that the fractional differences between NIR and MIR are consistent throughout all seasons, i.e., they are season-independent. Overall, NIR $\mathrm{X}_{\mathrm{HF}}$ data are in good agreement with the MIR $\mathrm{X}_{\mathrm{HF}}$ data, with a correlation coefficient (R) of 0.87 . As a result, we combine the two datasets to evaluate the seasonal cycles and long-term trend analyses of HF over Hefei. In a subsequent study, the mean bias of 2.15 pptv was applied to all individual NIR data.

\subsection{Seasonal and Interannual Variabilities}

In this part of the study, the combined time series of NIR and MIR observations were used to investigate the seasonal cycle and interannual trend of HF over Hefei, China. As shown in Figure 5, we have used the bootstrap resampling method of Gardiner et al. (2008) with a second Fourier series plus a linear function to fit the combined time series of $\mathrm{X}_{\mathrm{HF}}$ (Figure 5). Generally, the measured features in terms of seasonality and interannual variability from 2015 to 2020 can be reproduced by the bootstrap resampling model with a correlation coefficient $(\mathrm{R})$ of 0.81 . The seasonal cycle of HF derived from the combined data set is shown in Figure 6. As generally observed over Hefei, $X_{\mathrm{HF}}$ showed clear seasonal features, namely, (1) high levels of $X_{\mathrm{HF}}$ occur in the late winter to spring and low levels of $\mathrm{X}_{\mathrm{HF}}$ occur in later summer to autumn; (2) the variations in the late winter to spring are larger than those in later summer to autumn; and (3) seasonal cycle of $X_{\mathrm{HF}}$ over Hefei shows a unimodal pattern, i.e., the seasonal peak occurs around March and the seasonal trough occurs around September. 


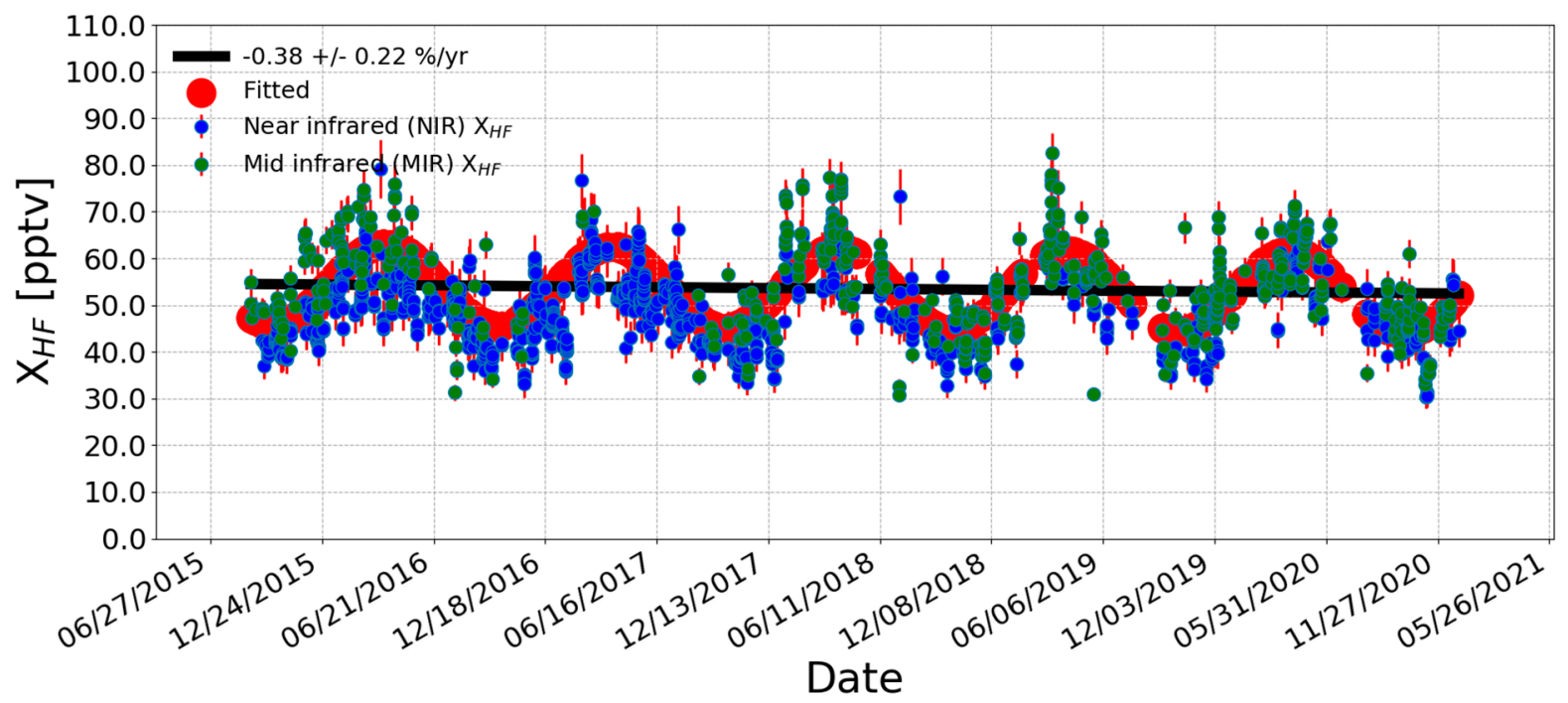

Figure 5. Time series of $\mathrm{X}_{\mathrm{HF}}$ daily mean for the combination of NIR and MIR observations.
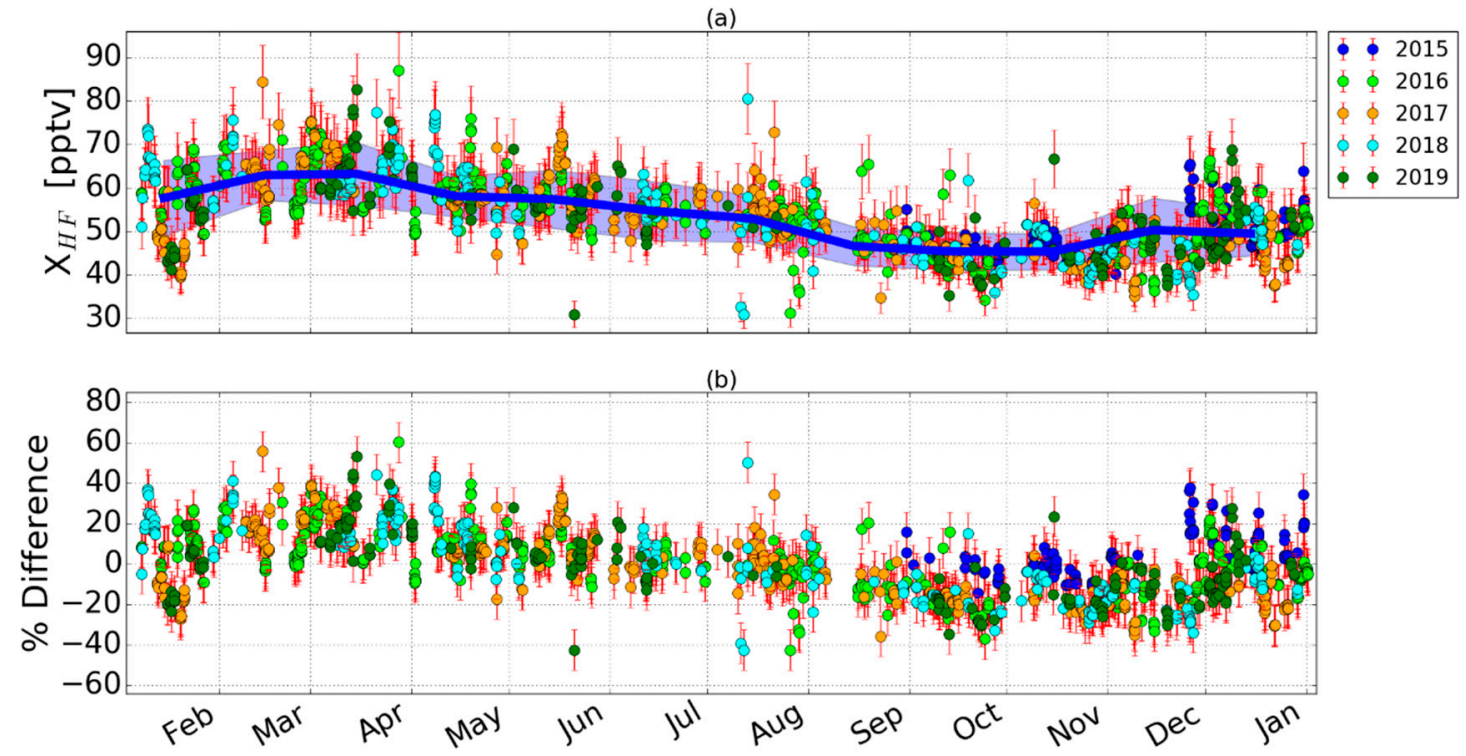

Figure 6. (a) Seasonal variations of FTIR $X_{\mathrm{HF}}$ from 2015 to 2020 over Hefei, eastern China. The blue line and the shadows represent monthly mean values of $\mathrm{X}_{\mathrm{HF}}$ and the 1- $\sigma$ standard variations, respectively. (b) Fractional differences of FTIR $\mathrm{X}_{\mathrm{HF}}$ time series relative to their seasonal mean values. Vertical error bars represent retrieval uncertainties.

The observed $\mathrm{X}_{\mathrm{HF}}$ showed a maximum monthly mean value of $(64.05 \pm 3.93)$ pptv in March and a minimum monthly mean value of $(45.15 \pm 2.93)$ pptv in September. The FTIR $\mathrm{X}_{\mathrm{HF}}$ values in March were on average $(29.51 \pm 5.22) \%$ higher than those in September. In terms of the HF total column, the maximum and minimum monthly mean values are $(1.28 \pm 0.17) \times 10^{15}$ molecules $/ \mathrm{cm}^{2}$ and $(0.57 \pm 0.16) \times 10^{15}$ molecules $/ \mathrm{cm}^{2}$, respectively The annual mean values of $\mathrm{X}_{\mathrm{HF}}$ and $\mathrm{HF}$ total column over Hefei are (53.70 \pm 5.90$) \mathrm{pptv}$ and $(0.97 \pm 0.18) \times 10^{15}$ molecules $/ \mathrm{cm}^{2}$, respectively. As commonly observed, the seasonal HF enhancements spanned a narrow range of $-42.0 \%$ to $50.0 \%$ depending on the season and measurement time (Figure 6). The observed HF time series from 2015 to 2020 showed a negative change rate of $(-0.38 \pm 0.22) \%$ per year (Figure 5$)$. Note that the calculation of the uncertainty in the trend in our study takes into account the autocorrelation in the residual, which increases the uncertainty. It turned out that, due to the chemical stable characteristic of HF in the stratosphere, the uncertainty in the trend is often too large to obtain significant value. 


\section{Discussion}

In this part of the study, we investigate the potential factors that drive the observed seasonality of $\mathrm{HF}$, which shows the maximum concentration in the late winter to spring and minimum concentration in later summer to autumn. Previous studies have found that the variability of chemical stable species such as hydrogen chloride $(\mathrm{HCl})$ in the stratosphere is generally controlled by the variability of the tropopause height, i.e., the seasonal cycle of $\mathrm{HCl}$ is inversely correlated with the tropopause height. The higher the tropopause height, the lower the stratospheric $\mathrm{HCl}$ concentration, and vice versa [23,37]. As one of the chemical stable species clusters in the stratosphere, we compared the seasonal cycle of HF with the variability of tropopause height over Hefei. The tropopause height data used in this study were prescribed from GEOS-Chem chemistry transport model simulation driven by Goddard Earth Observing System-forward-processing (GEOS-FP) meteorological fields (ftp:/ / rain.ucis.dal.ca/ctm/, accessed on 5 January 2021) at a horizontal resolution of $2^{\circ} \times 2.5^{\circ}$ degraded from their native resolution of $0.25^{\circ} \times 0.3125^{\circ}$. The GEOS-Chem model outputs tropopause height around the globe at a temporal resolution of $1 \mathrm{hr}$ and a spatial resolution of $2^{\circ} \times 2.5^{\circ}$. We only considered the tropopause height daily mean simulations from 2015 to 2020 in the grid box containing Hefei $\left(31.52^{\circ}-32.11^{\circ} \mathrm{N}\right.$ by $\left.116.53^{\circ}-118.02^{\circ} \mathrm{E}\right)$.

Comparison between seasonal cycles of tropopause height and $\mathrm{X}_{\mathrm{HF}}$ over Hefei is presented in Figure 7. Correlation plots of daily mean time series of tropopause height against FTIR $X_{\mathrm{HF}}$ measurements are shown in Figure 8. In contrast to the seasonal cycle of $X_{\mathrm{HF}}$, the tropopause height over Hefei showed a maximum monthly mean value of $16.31 \mathrm{~km}$ in August and a minimum monthly mean value of $13.76 \mathrm{~km}$ in March. The variability of $\mathrm{X}_{\mathrm{HF}}$ is inversely correlated with the tropopause height with a correlation coefficient (R) of -0.54 . As a result, the variability of tropopause height is a key factor that drives the variability of HF in the stratosphere. With higher tropopause height in summer and autumn, more stratospheric HF moves downward to the troposphere and then is removed through wet deposition along with rainfall or destroyed by photolysis, resulting in lower stratospheric HF concentration in these seasons, and vice versa for higher stratospheric HF concentration in late winter and spring [23,37]. The mechanism between tropopause height and stratospheric HF transport mainly via the stratosphere-troposphere exchange (STE) process, rainfall, and dynamic transmission [38]. In addition, the photolysis destruction in summer to autumn is stronger than those in the winter to spring, which serves as an additional important role for driving the seasonal cycle of HF in the stratosphere [23,35].

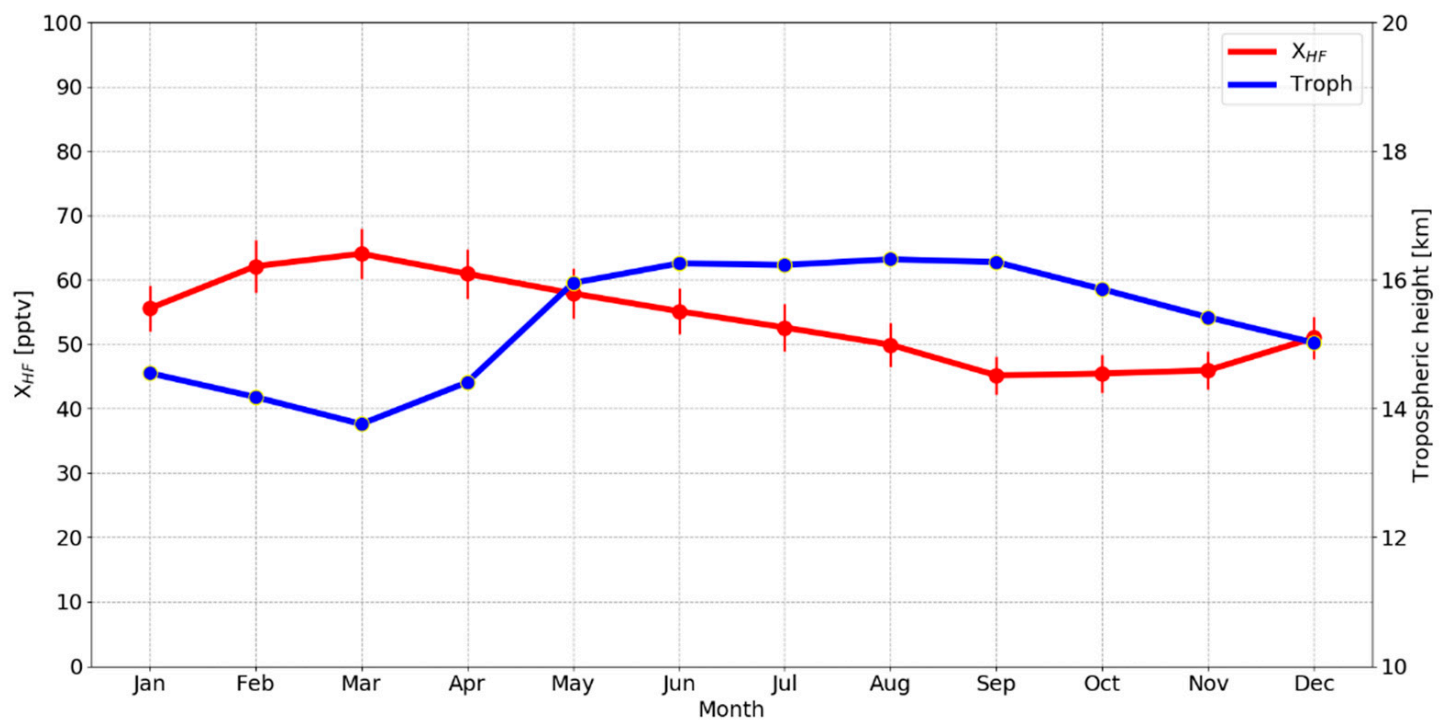

Figure 7. Comparison between monthly mean values of $\mathrm{X}_{\mathrm{HF}}$ and tropopause height over Hefei, China. 


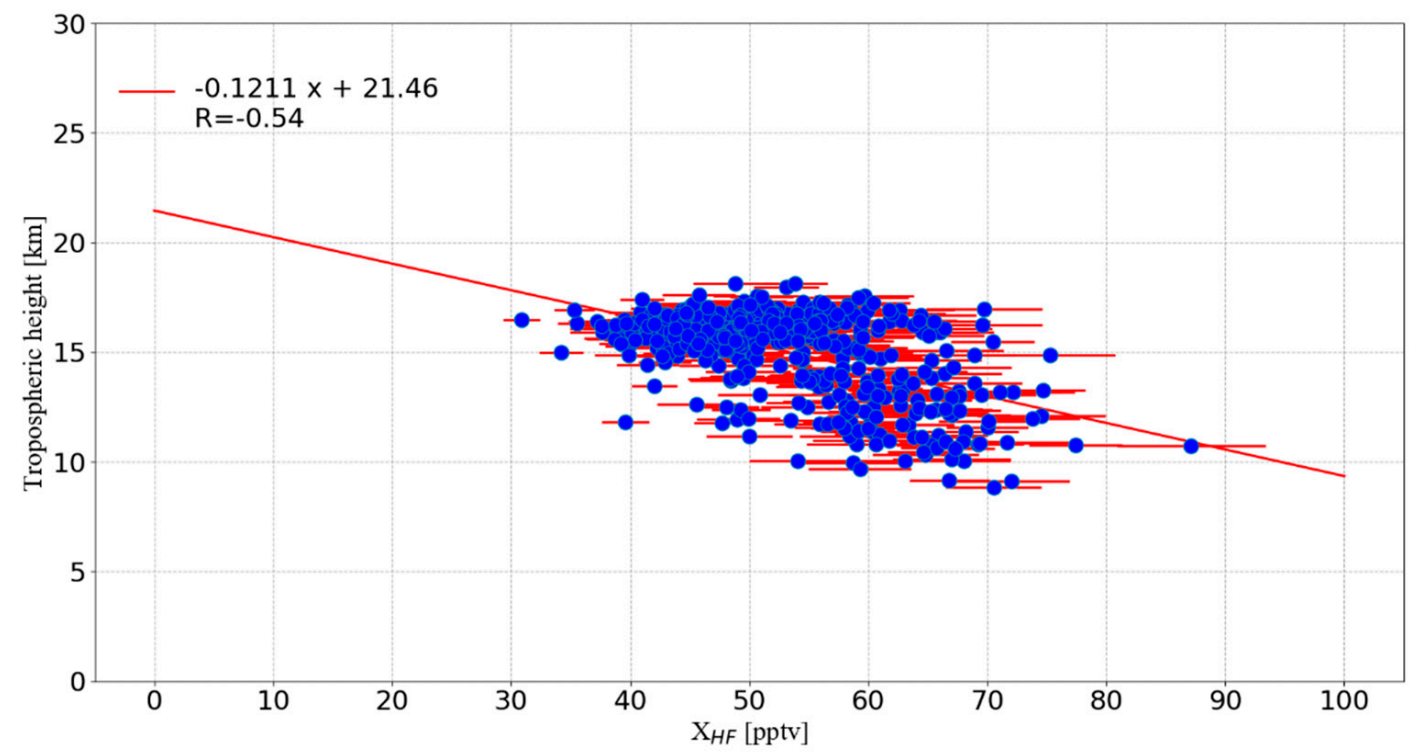

Figure 8. Correlation plots of $\mathrm{X}_{\mathrm{HF}}$ daily mean measurements against tropopause height over Hefei, China. The red line is the linear fitted curve of respective scatter points.

\section{Conclusions}

Monitoring hydrogen fluoride (HF) as part of the atmospheric fluorine family plays an important role in assessing the fluorine budget. However, the coverage of global HF measurements remains sparse since it is challenging to find robust measurement techniques for this species that has weak absorption signatures in the atmosphere but surrounded by strong lines from interfering gases.

In this study, we first presented a multi-year time series of HF total columns over Hefei, China by using high-resolution ground-based Fourier transform infrared (FTIR) spectrometry. Both near-infrared (NIR) and mid-infrared (MIR) solar spectra suites, which are recorded following the requirements of Total Carbon Column Observing Network (TCCON) and Network for the Detection of Atmospheric Composition Change (NDACC), respectively, were used to retrieve total column of $\mathrm{HF}\left(\mathrm{T}_{\mathrm{HF}}\right)$ and column-averaged dry-air mole fractions of $\mathrm{HF}\left(\mathrm{X}_{\mathrm{HF}}\right)$. Spectroscopic retrievals of HF with both NIR and MIR observations were characterized and compared. The NIR and MIR observations are generally in good agreement with a correlation coefficient $(\mathrm{R})$ of 0.87 , but the NIR observations are found to be $(6.90 \pm 1.07)$ pptv lower than the MIR measurements. By correcting this bias, the combination of NIR and MIR observations discloses that the $\mathrm{X}_{\mathrm{HF}}$ over Hefei showed a maximum monthly mean value of $(64.05 \pm 3.93)$ pptv in March and a minimum monthly mean value of $(45.15 \pm 2.93)$ pptv in September. The FTIR $X_{\mathrm{HF}}$ values in March were on average ( $29.51 \pm 5.22) \%$ higher than those in September. In terms of the HF total column, the maximum and minimum monthly mean values are $(1.28 \pm 0.17) \times 10^{15}$ molecules $/ \mathrm{cm}^{2}$ and $(0.57 \pm 0.16) \times 10^{15}$ molecules $/ \mathrm{cm}^{2}$, respectively. The observed $\mathrm{X}_{\mathrm{HF}}$ time series from 2015 to 2020 showed a negative trend of $(-0.38 \pm 0.22) \%$ per year. The variability of $\mathrm{X}_{\mathrm{HF}}$ is inversely correlated with the tropopause height, indicating that the variability of tropopause height is a key factor for driving the seasonal cycle of HF in the stratosphere. With higher tropopause height in summer and autumn, more stratospheric HF transport downward to the troposphere and then are removed through wet deposit along with rainfall or destroyed by photolysis, resulting in lower stratospheric HF concentration in these seasons, and vice versa for higher stratospheric HF concentration in late winter and spring.

This study can enhance the understanding of ground-based high-resolution remote sensing techniques for atmospheric HF and its evolution in the stratosphere and contribute to forming new reliable remote sensing data in this sparsely monitored region for research on climate change. 
Author Contributions: Conceptualization, H.Y. and Y.S.; methodology, H.Y. and Y.S.; software, H.Y. and Y.S.; validation, H.Y.; Y.S.; W.W.; C.S. and L.Z.; formal analysis, H.Y. and Y.S.; investigation, H.Y.; Y.S.; W.W.; C.G. and L.Z.; retrieval process, H.Y.; Y.S. and L.Z.; data curation, H.Y.; Y.S.; W.W.; C.S. and L.Z.; writing-original draft preparation, H.Y. and Y.S.; writing-review and editing, H.Y. and Y.S.; visualization, H.Y.; supervision, C.L.; project administration, Y.S. and C.L.; funding acquisition, Y.S. and C.L. All authors have read and agreed to the published version of the manuscript.

Funding: This research was funded by the National Key Research and Development Program of China (No. 2019YFC0214802, No. 2017YFC0210002, No. 2016YFC0203302, 2018YFC0213201, 2019YFC0214702, 2016YFC0200404), the National Science Foundation of China (No. 41775025, No. 41575021, No. 51778596, No. 91544212, No. 41722501, No. 51778596), and the Sino-German Mobility Program (M-0036).

Data Availability Statement: The data presented in this study are available on request from the corresponding author.

Acknowledgments: The processing environment of SFIT4 and some plot programs are provided by the National Center for Atmospheric Research (NCAR), Boulder, CO, USA. The NDACC networks are acknowledged for supplying the SFIT software and advice. The TCCON networks are acknowledged for supplying the GFIT software and advice. The LINEFIT code is provided by Frank Hase, Karlsruhe Institute of Technology (KIT), Institute for Meteorology and Climate Research (IMK-ASF), Germany. We thank the FTIR groups at the University of Bremen, Germany, and the University of Wollongong, Australia, for their help in setting up the retrieval and operating the FTIR spectrometer at Hefei. We thank Ziheng Song for his contribution to the work of validation, retrieval process, data curation and investigation.

Conflicts of Interest: The authors declare no conflict of interest.

\section{References}

1. Mahieu, E.; Duchatelet, P.; Demoulin, P.; Walker, K.A.; Dupuy, E.; Froidevaux, L.; Randall, C.; Catoire, V.; Strong, K.; Boone, C.D.; et al. Validation of ACE-FTS v2.2 measurements of $\mathrm{HCl}, \mathrm{HF}, \mathrm{CCl}_{3} \mathrm{~F}$ and $\mathrm{CCl}_{2} \mathrm{~F}_{2}$ using space-, balloon- and ground-based instrument observations. Atmos. Chem. Phys. 2008, 8, 6199-6221. [CrossRef]

2. Steffen, J.; Bernath, P.F.; Boone, C.D. Trends in halogen-containing molecules measured by the Atmospheric Chemistry Experiment (ACE) satellite. J. Quant. Spectrosc. Radiat. Transf. 2019, 238, 106619. [CrossRef]

3. Tegtmeier, S.; Hegglin, M.I.; Anderson, J.; Funke, B.; Walker, K.A. The SPARC Data Initiative: Comparisons of CFC-11, CFC-12, $\mathrm{HF}$ and $\mathrm{SF}_{6}$ climatologies from international satellite limb sounders. Earth Syst. Sci. Data 2016, 8, 61-78. [CrossRef]

4. Brown, A.T.; Chipperfield, M.P.; Richards, N.A.D.; Boone, C.; Bernath, P.F. Global stratospheric fluorine inventory for 2004-2009 from Atmospheric Chemistry Experiment Fourier Transform Spectrometer (ACE-FTS) measurements and SLIMCAT model simulations. Atmos. Chem. Phys. 2014, 14, 267-282. [CrossRef]

5. Tressaud, A. Fluorine and the Environment: Atmospheric Chemistry, Emissions \& Lithosphere; Advances in Fluorine Science; Elsevier Science: Amsterdam, The Netherlands, 2006.

6. Duchatelet, P.; Demoulin, P.; Hase, F.; Ruhnke, R.; Feng, W.; Chipperfield, M.P.; Bernath, P.F.; Boone, C.D.; Walker, K.A.; Mahieu, E. Hydrogen fluoride total and partial column time series above the Jungfraujoch from long-term FTIR measurements: Impact of the line-shape model, characterization of the error budget and seasonal cycle, and comparison with satellite and model data. J. Geophys. Res. Atmos. 2010, 115. [CrossRef]

7. Harrison, J.J.; Chipperfield, M.P.; Boone, C.D.; Dhomse, S.S.; Russell, J. Satellite observations of stratospheric hydrogen fluoride and comparisons with SLIMCAT calculations. Atmos. Chem. Phys. 2015, 15, 34361-34405.

8. Rinsland, C.P.; Boone, C.; Nassar, R.; Walker, K.; Bernath, P.; Mahieu, E.; Zander, R.; McConnell, J.C.; Chiou, L. Trends of HF, $\mathrm{HCl}, \mathrm{CCl}_{2} \mathrm{~F}_{2}, \mathrm{CCl}_{3} \mathrm{~F}, \mathrm{CHClF}_{2}$ (HCFC-22), and SF6 in the lower stratosphere from Atmospheric Chemistry Experiment (ACE) and Atmospheric Trace Molecule Spectroscopy (ATMOS) measurements near $30^{\circ} \mathrm{N}$ latitude. Geophys. Res. Lett. 2005, 32. [CrossRef]

9. Mikuteit, S. Trendbestimmung Stratosphärischer Spurengase Mit Hilfe Bodengebundener FTIR-Messungen. Ph.D. Thesis, Forschungszentrum Karlsruhe, Karlsruhe, Germany, 2008.

10. Kohlhepp, R.; Barthlott, S.; Blumenstock, T.; Hase, F.; Kaiser, I.; Raffalski, U.; Ruhnke, R. Trends of $\mathrm{HCl}_{1} \mathrm{ClONO}_{2}$, and HF column abundances from ground-based FTIR measurements in Kiruna (Sweden) in comparison with KASIMA model calculations. Atmos. Chem. Phys. 2011, 11, 4669-4677. [CrossRef]

11. Messerschmidt, J.; Macatangay, R.; Notholt, J.; Petri, C.; Warneke, T.; Weinzierl, C. Side by side measurements of $\mathrm{CO}_{2}$ by ground-based Fourier transform spectrometry (FTS). Tellus B 2010, 62, 749-758. [CrossRef]

12. Washenfelder, R.A.; Toon, G.C.; Blavier, J.F.; Yang, Z.; Allen, N.T.; Wennberg, P.O.; Vay, S.A.; Matross, D.M.; Daube, B.C. Carbon dioxide column abundances at the Wisconsin Tall Tower site. J. Geophys. Res. Atmos. 2006, 111, D22305. [CrossRef] 
13. Wunch, D.; Toon, G.C.; Blavier, J.F.L.; Washenfelder, R.A.; Notholt, J.; Connor, B.J.; Griffith, D.W.T.; Sherlock, V.; Wennberg, P.O. The Total Carbon Column Observing Network. Philos. Trans. R. Soc. A 2011, 369, 2087-2112. [CrossRef] [PubMed]

14. Wunch, D.; Toon, G.C.; Wennberg, P.O.; Wofsy, S.C.; Stephens, B.B.; Fischer, M.L.; Uchino, O.; Abshire, J.B.; Bernath, P.; Biraud, S.C.; et al. Calibration of the Total Carbon Column Observing Network using aircraft profile data. Atmos. Meas. Tech. 2010, 3, 1351-1362. [CrossRef]

15. Angelbratt, J.; Mellqvist, J.; Simpson, D.; Jonson, J.E.; Blumenstock, T.; Borsdorff, T.; Duchatelet, P.; Forster, F.; Hase, F.; Mahieu, E.; et al. Carbon monoxide $(\mathrm{CO})$ and ethane $\left(\mathrm{C}_{2} \mathrm{H}_{6}\right)$ trends from ground-based solar FTIR measurements at six European stations, comparison and sensitivity analysis with the EMEP model. Atmos. Chem. Phys. 2011, 11, 9253-9269. [CrossRef]

16. Zhou, M.; Langerock, B.; Vigouroux, C.; Sha, M.K.; Hermans, C.; Metzger, J.M.; Chen, H.; Ramonet, M.; Kivi, R.; Heikkinen, P.; et al. TCCON and NDACC XCO measurements: Difference, discussion and application. Atmos. Meas. Tech. 2019, 12, 5979-5995. [CrossRef]

17. Zhou, M.; Langerock, B.; Wells, K.C.; Millet, D.B.; Vigouroux, C.; Sha, M.K.; Hermans, C.; Metzger, J.M.; Kivi, R.; Heikkinen, P.; et al. An intercomparison of total column-averaged nitrous oxide between ground-based FTIR TCCON and NDACC measurements at seven sites and comparisons with the GEOS-Chem model. Atmos. Meas. Tech. 2019, 12, 1393-1408. [CrossRef]

18. Sun, Y.W.; Liu, C.; Palm, M.; Vigouroux, C.; Notholt, J.; Hui, Q.H.; Jones, N.; Wang, W.; Su, W.J.; Zhang, W.Q.; et al. Ozone seasonal evolution and photochemical production regime in the polluted troposphere in eastern China derived from high-resolution Fourier transform spectrometry (FTS) observations. Atmos. Chem. Phys. 2018, 18, 14569-14583. [CrossRef]

19. Sun, Y.; Yin, H.; Liu, C.; Zhang, L.; Cheng, Y.; Palm, M.; Notholt, J.; Lu, X.; Vigouroux, C.; Zheng, B.; et al. Mapping the drivers of formaldehyde (HCHO) variability from 2015-2019 over eastern China: Insights from FTIR observation and GEOS-Chem model simulation. Atmos. Chem. Phys. Discuss. 2020, 2020, 1-24. [CrossRef]

20. Sun, Y.W.; Liu, C.; Zhang, L.; Palm, M.; Notholt, J.; Hao, Y.; Vigouroux, C.; Lutsch, E.; Wang, W.; Shan, C.G.; et al. Fourier transform infrared time series of tropospheric HCN in eastern China: Seasonality, interannual variability, and source attribution. Atmos. Chem. Phys. 2020, 20, 5437-5456. [CrossRef]

21. Tian, Y.; Sun, Y.W.; Liu, C.; Wang, W.; Shan, C.G.; Xu, X.W.; Hu, Q.H. Characterisation of methane variability and trends from near-infrared solar spectra over Hefei, China. Atmos. Environ. 2018, 173, 198-209. [CrossRef]

22. Wang, W.; Tian, Y.; Liu, C.; Sun, Y.W.; Liu, W.Q.; Xie, P.H.; Liu, J.G.; Xu, J.; Morino, I.; Velazco, V.A.; et al. Investigating the performance of a greenhouse gas observatory in Hefei, China. Atmos. Meas. Tech. 2017, 10, 2627-2643. [CrossRef]

23. Yin, H.; Sun, Y.W.; Liu, C.; Lu, X.; Smale, D.; Blumenstock, T.; Nagahama, T.; Wang, W.; Tian, Y.; Hu, Q.H.; et al. Ground-based FTIR observation of hydrogen chloride $(\mathrm{HCl})$ over Hefei, China, and comparisons with GEOS-Chem model data and other ground-based FTIR stations data. Opt. Express 2020, 28, 8041-8055. [CrossRef] [PubMed]

24. Yin, H.; Sun, Y.W.; Liu, C.; Zhang, L.; Lu, X.; Wang, W.; Shan, C.G.; Hu, Q.H.; Tian, Y.; Zhang, C.X.; et al. FTIR time series of stratospheric $\mathrm{NO}_{2}$ over Hefei, China, and comparisons with OMI and GEOS-Chem model data. Opt. Express 2019, 27, A1225-A1240. [CrossRef] [PubMed]

25. Shan, C.G.; Wang, W.; Liu, C.; Sun, Y.W.; Hu, Q.H.; Xu, X.W.; Tian, Y.; Zhang, H.F.; Morino, I.; Griffit, D.W.T.; et al. Regional CO emission estimated from ground-based remote sensing at Hefei site, China. Atmos. Res. 2019, 222, 25-35. [CrossRef]

26. Sun, Y.W.; Palm, M.; Liu, C.; Hase, F.; Griffith, D.; Weinzierl, C.; Petri, C.; Wang, W.; Notholt, J. The influence of instrumental line shape degradation on NDACC gas retrievals: Total column and profile. Atmos. Meas. Tech. 2018, 11, 2879-2896. [CrossRef]

27. Wunch, D.; Toon, G.C.; Sherlock, V.; Deutscher, N.M.; Liu, X.; Feist, D.G.; Wennberg, P.O. The Total Carbon Column Observing Network's GGG2014 Data Version. CaltechDATA 2015. [CrossRef]

28. Kalnay, E.; Kanamitsu, M.; Kistler, R.; Collins, W.; Deaven, D.; Gandin, L.; Iredell, M.; Saha, S.; White, G.; Woollen, J.; et al. The NCEP/NCAR 40-year reanalysis project. Am. Meteorol. Soc. 1996, 77, 437-471. [CrossRef]

29. Hill, C.; Gordon, I.E.; Rothman, L.S.; Tennyson, J. A new relational database structure and online interface for the HITRAN database. J. Quant. Spectrosc. Radiat. Transf. 2013, 130, 51-61. [CrossRef]

30. Rothman, L.S.; Gordon, I.E.; Barbe, A.; Benner, D.C.; Bernath, P.F.; Birk, M.; Boudon, V.; Brown, L.R.; Campargue, A.; Champion, J.P.; et al. The HITRAN 2008 molecular spectroscopic database. J. Quant. Spectrosc. Radiat. Transf. 2009, 110, 533-572. [CrossRef]

31. Hase, F. Improved instrumental line shape monitoring for the ground-based, high-resolution FTIR spectrometers of the Network for the Detection of Atmospheric Composition Change. Atmos. Meas. Tech. 2012, 5, 603-610. [CrossRef]

32. Hase, F.; Blumenstock, T.; Paton-Walsh, C. Analysis of the instrumental line shape of high-resolution Fourier transform IR spectrometers with gas cell measurements and new retrieval software. Appl. Opt. 1999, 38, 3417-3422. [CrossRef]

33. Rodgers, C. Inverse Methods for Atmospheric Sounding-Theory and Practice; World Scientific: Singapore, 2000; Volume 2. [CrossRef]

34. Rodgers, C.D.; Connor, B.J. Intercomparison of remote sounding instruments. J. Geophys. Res. Atmos. 2003, 108. [CrossRef]

35. Gardiner, T.; Forbes, A.; de Maziere, M.; Vigouroux, C.; Mahieu, E.; Demoulin, P.; Velazco, V.; Notholt, J.; Blumenstock, T.; Hase, F.; et al. Trend analysis of greenhouse gases over Europe measured by a network of ground-based remote FTIR instruments. Atmos. Chem. Phys. 2008, 8, 6719-6727. [CrossRef]

36. Santer, B.D.; Thorne, P.W.; Haimberger, L.; Taylor, K.E.; Wigley, T.M.L.; Lanzante, J.R.; Solomon, S.; Free, M.; Gleckler, P.J.; Jones, P.D.; et al. Consistency of modelled and observed temperature trends in the tropical troposphere. Int. J. Clim. 2008, 28, 1703-1722. [CrossRef] 
37. Kohlhepp, R.; Ruhnke, R.; Chipperfield, M.P.; De Maziere, M.; Notholt, J.; Barthlott, S.; Batchelor, R.L.; Blatherwick, R.D.; Blumenstock, T.; Coffey, M.T.; et al. Observed and simulated time evolution of $\mathrm{HCl}, \mathrm{ClONO}_{2}$, and HF total column abundances. Atmos. Chem. Phys. 2012, 12, 3527-3556. [CrossRef]

38. Vigouroux, C.; De Mazière, M.; Demoulin, P.; Servais, C.; Hase, F.; Blumenstock, T.; Kramer, I.; Schneider, M.; Mellqvist, J.; Strandberg, A.; et al. Evaluation of tropospheric and stratospheric ozone trends over Western Europe from ground-based FTIR network observations. Atmos. Chem. Phys. 2008, 8, 6865-6886. [CrossRef] 